On the other hand, live vaccines may mutate; rarely they may revert to virulence during growth in vaccinees and so cause paralytic poliomyelitis in recipients or their contacts. (For that reason all susceptible family members should be vaccinated simultaneously to minimise the chance of reverted virus being transmitted to non-immune close contacts.) These risks should not be exaggerated: a five-year study by a special committee of $\mathrm{WHO}^{11}$ showed attack rates in recipients varying from 0 to 2 per million doses of vaccine distributed (one per 4 million doses adminstered in England and Wales ${ }^{12}$ ). Most of those affected were children under 5 years old infected with type 3 virus; the rates in contacts ranged from 0.1 to 0.6 per million doses, except in two high-incidence countries which had used high-passage seed virus without continuous control. Most of these contact infections were by type 2 virus, often in non-immune parents of recently vaccinated infants in countries which, like Britain, vaccinate throughout the year. In countries which concentrate polio vaccination into short campaigns most cases were in children under 5 years old. These are maximal estimates of risk, based on circumstantial evidence: no laboratory test can yet identify unequivocally whether a particular strain of poliovirus has originated from vaccine or otherwise. The potential of live vaccine progeny to spread to close contacts, formerly regarded as an advantage, is nowadays considered a disadvantage. This unlicensed progeny virus may also spread to persons in the community who have not agreed to be vaccinated.

In some countries with warm climates oral vaccine fails to induce immunity in a satisfactorily high proportion of recipients. This failure may be due to interference by hyperendemic enteroviruses or more probably to immunoglobulinlike inhibitors in infants' saliva, ${ }^{13}$ which may be combated by simultaneous administration of equine antibody to human gammaglobulin or by giving repeated doses of vaccine. Finally, the live vaccine is contraindicated in persons with immunodeficiency diseases or on immunosuppressive treatment, and in their household contacts.

The WHO report confirmed that “. . . poliomyelitis vaccines (oral) made from the Sabin attenuated strains are among the safest vaccines in use today." There is no adequate reason for countries using the inexpensive and efficient oral vaccine to change to the inactivated vaccine. Equally there appears to be no reason for the opposite change by countries which can afford to use inactivated vaccine of high quality on the scale necessary to prevent poliomyelitis. But the price of freedom from polio is eternal vigilance: whatever the type of vaccine in use, it must be the subject of continued laboratory and epidemiological control. Surveillance of the population must include antibody surveys to detect gaps in immunity which may indicate failure of the vaccine or of its uptake by the population.

\footnotetext{
${ }^{1}$ Paul, J R, Bulletin of the World Health Organisation, 1958, 19, 747.

2 Nicholas, D D, et al, British Medical fournal, 1977, 1, 1009.

${ }^{3}$ Ofosu-Amaah, S, Kratzer, J H, and Nicholas, D D, British Medical fournal, 1977, 1, 1012.

${ }^{4}$ World Health Organisation, Weekly Epidemiological Record, 1977, 52, 138.

5 Bijkerk, H, et al, Nederlands Tijdschrift voor Geneeskunde, 1972, 116, 549.

6 World Health Organisation, Weekly Epidemiological Record, 1978, 53, 187.

7 World Health Organisation, Regional Office for Europe, Communicable Diseases: Methods of Surveillance. Report on a seminar, The Hague, 1969. Copenhagen, World Health Organisation, 1969.

${ }^{8}$ Melnick, J L, Bulletin of the World Health Organisation, 1978, 56, 21.

${ }_{9}^{9}$ Dick, G W A, et al, British Medical fournal, 1961, 2, 266.

${ }_{10}$ Reid, D, et al, Lancet, 1969, 1, 564.

11 Assaad, F, et al, Bulletin of the World Health Organisation, 1976, 53, 319.

${ }_{12}$ Miller, D, Reid, D, and Diamond, J R, Public Health, London, 1970, 84, 265.

${ }^{13}$ Domok, I, Bulletin of the World Health Organisation, 1974, 51, 333.
}

\section{Nutrition and the patient with cancer}

Nutritional depletion is a common hallmark of patients with $\stackrel{.}{\hookrightarrow}$ cancer. Many factors may contribute to the characteristic $\overrightarrow{\vec{F}}$ cachexia. Clinically, there is loss of body protein and fat, $\overrightarrow{0}$ anaemia, electrolyte disturbances, and weakness and debility. 을 Anorexia is a major problem, and many patients seem satisfied $\frac{\bar{m}}{\sigma}$ by a little intake. Emotional problems such as depression may $\underset{\complement}{\complement}$

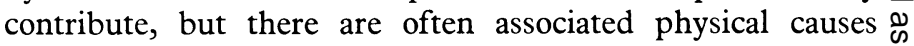
such as ulceration and infection of the mouth, nausea, and $\vec{\theta}$ vomiting, and there may be abnormalities of taste-in particular, blunting of the sense of sweetness, heightened sensi- $\vec{\omega}$ tivity to bitterness, and aversion to meat. ${ }^{1}$ Whatever its cause, $\frac{\partial}{\partial}$ the management of the anorexia requires psychological support, good preparation of food, and the elimination of oral $\frac{N}{\sigma}$ infection if the patient is to eat enough. Mechanical obstruction of the gastrointestinal tract or the biliary or pancreatic ducts $\vec{\Phi}$ and fistula formation may also contribute to the cachexia by $\frac{\infty}{\circ}$ limiting intake or absorption; while tumour necrosis, ulcera- 0 tion, associated infection, and haemorrhage all result in excessive loss of protein.

Some specific changes are seen in animals and patients with $\mathbb{D}$ cancer but not in starvation. Calman and McAllister ${ }^{2}$ reported $\frac{\vec{D}}{D}$ a fall in the co-enzyme A content of liver and muscle within $\bar{Z}$ 24 hours of implanting tumours in animals, with the implica- $\frac{\mathbb{D}}{-}$ tion that $\beta$-oxidation of fatty acids is impaired. Warnold $\vec{\theta}$ et $a l^{3}$ compared energy balance in patients with cancer with $\propto$ controls free from malignant disease. Though they found no 0 significant difference in energy intake, they confirmed Pratt's $\mathrm{s}^{4} \sum_{\Sigma}^{\circ}$ results in animal studies and found energy expenditure and $\overline{0}$ resting metabolic rate were significantly increased in the patients with cancer. This increased energy expenditure may $\stackrel{\varnothing}{\stackrel{D}{2}}$ be an additional cause of cachexia. After curative surgery $\overrightarrow{\overrightarrow{0}}$ energy expenditure returned to the control values.

At a recent symposium at the University of Surrey special emphasis was placed on the vitamin requirements of patients with cancer. Vitamin A deficiency is associated with tumours of the gastrointestinal tract, nasopharynx, and lung. ${ }^{5}$ Since vitamin A may be important in maintaining adequate serum $\frac{5}{3}$ concentrations of non-specific opsonins ${ }^{6}$ and is an effective immunostimulant, ${ }^{7}$ depletion may depress the immune res- $\frac{0}{3}$ ponse. Low leucocyte concentrations of vitamin $\mathrm{C}$ have been described in patients with bone metastases from carcinoma of the breast-a finding associated with depression of phago- $\sigma$ cytosis by neutrophils, ${ }^{8}$ reduced macrophage migration, ${ }^{9} \frac{D}{O}$ increased incidence of wound dehiscence, ${ }^{10}$ and alterations in drug metabolism.

Surgery, chemotherapy, and radiotherapy, singly or in $\mathrm{\omega}^{\circ}$ combination, may further compromise the nutritional state

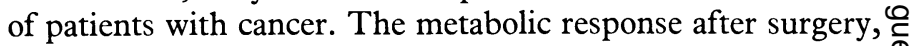
with its associated loss of lean tissue, is well documented, but $\stackrel{\Phi}{\rightleftharpoons}$ further depletion may be associated with cancer chemotherapy. 0 Some chemotherapeutic agents are analogues of essential nutrients: methotrexate, for example, is an antagonist of folic $\stackrel{\Phi}{\Phi}$ acid. A sprue-like syndrome with the characteristic malabsorp- $\mathbb{\mathbb { D }}$ tion may be produced by agents such as 5-fluouracil, which induces morphological and biochemical changes in the gastro- $\delta$ intestinal mucosa: typically the height of the villi is reduced and intestinal dipeptidases are depleted, so impairing assimila-

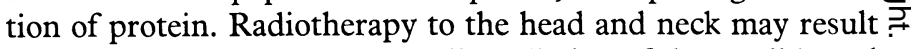
in stomatitis and dysphagia, while radiation of the small bowel may cause oedema and endarteritis of small blood vessels, 
impairing absorption and causing protein loss from necrosis and ulceration.

With so many factors that may contribute to the pathogenesis of cachexia in the individual patient their relative importance may be difficult to determine. The presence of nutritional depletion may be detected very simply: a recent loss of $10 \%$ of total body weight, a serum albumin concentration of less than $34 \mathrm{~g} / \mathrm{l}$, and a negative reaction to a battery of skin test antigens. Patients depleted on the basis of those criteria require aggressive nutritional repletion (through the gut or by infusion) with the aim of preventing death from debility or infection, reducing the incidence of wound dehiscence, enhancing the immune response, and extending the limits of tolerance of cancer treatment.

${ }^{1}$ De Wys, N D, and Walters, K, Cancer, 1975, 36, 1888.

2 Calman, K C, and McAllister, R D, British fournal of Cancer, 1975, 32, 247.

3 Warnold, I, Lundholm, K, and Schersten, T, Cancer Research, 1978, 38, 1801.

${ }^{4}$ Pratt, A W, and Putney, F K, fournal of the National Cancer Institute, 1958, 20, 173.

${ }^{5}$ Dickerson, J W T, Nutrition Bulletin, 1978, 4(4), 247.

6 Axelrod, A E, American fournal of Clinical Nutrition, 1971, 24, 265.

7 Jurin, M, and Tannock, I F, Immunology, 1972, 23, 283.

${ }^{8}$ Nungester, W J, and Ames, A M, Fournal of Infectious Diseases, 1948, 83, 50.

${ }^{9}$ Ganguly, R, Durieux, M F, and Waldman, R H, American fournal of Clinical Nutrition, 1976, 29, 762.

${ }^{10}$ Crandon, J H, et al, Annals of the New York Academy of Sciences, 1961, 92, 246.

\section{Living with multiple sclerosis}

The onset of multiple sclerosis is often frightening. Frequently it induces a feeling of loss, like bereavement; "the old self has to go and a new self grow in its place." This search for new ways of coping was discussed by Dr Alexander Burnfield at a study day held recently by the Multiple Sclerosis Society. Much of what he said could be applied to any disabling condition of adult life. Patients' needs should ideally be the concern of their general practitioners, who can at least open the way to other sources of help. Sadly, once the patient is in the hands of a consultant the family doctor's responsibility often seems to decline, or else he may feel too busy or unequipped to probe wider problems. At all events, many patients evidently do not feel they have support from their GPs.

Counselling may make all the difference between adjustment and serious psychological problems later on. Perhaps eventually it will become standard practice for all patients with multiple sclerosis ${ }^{1}$; but meanwhile family doctors (for there may be no one else to whom the patient can easily turn) should ensure that some counsellor is available to the patient for as long as necessary. Such a person need not be a professional, so long as he or she has the time to listen and a capacity for empathy and knows where expert help may be found. The Multiple Sclerosis Society often helps in this way. Sometimes the initial "mourning" process goes wrong and severe depression or even paranoid fantasies or a manic state may result; again, Dr Burnfield said, the family doctor should be aware of what is going on and consider psychotherapy and not just prescribe tranquillisers. The vulnerable personality calls for particular watchfulness: the happy-go-lucky person tends to fare best, whereas someone who has coped badly with minor problems, or the obsessional, controlled type of person, may need special help-as do those who have no supporting relationships in their life.

Many marriages break up because of multiple sclerosis. ${ }^{1}$ Here again the doctor needs to be watchful so that the couple can receive help at an early stage. Specifically sexual difficulties, even if permanent, may also be capable of some remedy. In some cases the family itself becomes sick, perhaps with intense guilt and hostility, and sometimes serious manipulation by the patient; early counselling may help to reduce such engulfing problems.

For all of us the quality of life is influenced also by simple practical things, and $\mathrm{Mr}$ Roger Jefcoate showed some of the technical aids that can improve the lives of those handicapped by multiple sclerosis or other disabilities. The needs of the severely handicapped are not likely to go unnoticed, but people with moderate disablement may struggle on with restrictions that could be lightened by simple gadgets. Health workers should bear in mind devices such as sonic torches for remote control of electrical equipment, modified switches, and two-way intercom units, which can increase both independence and peace of mind. As a general principle, we must always ask what the patient can still do and in what ways technology (or other help) can compensate for lost abilities.

Central to the patient's adjustment is the extent to which he develops a new identity and inner security and learns to live comfortably with himself and others. Quite simple ideas may help develop new forms of fulfilment. Work is important to the self-image, but a full-time job may be too taxing. Employers could help by offering part-time work, even when this is not usual, for it can save patients from the degradation of unemployment (though with a little imagination work at home often becomes possible). Sick or disabled people may also be demoralised by being so often "on the receiving end." They can often be helped by helping others.

${ }^{1}$ Burnfield, A, and Burnfield, P, British Medical fournal, 1978, 1, 1193.

\section{Chenic acid for gall stones}

Chenic (or chenodeoxycholic) acid has recently become generally available by prescription for treating cholesterol gall stones medically. First isolated from goose bile (Greek chen, goose), chenic acid makes up about $40 \%$ of the bile acids present in normal human bile. During successful treatment the proportion of chenic acid in bile rises to over $70 \%$. This reduces cholesterol secretion into bile, ${ }^{1}$ probably by inhibiting cholesterol synthesis in the liver. ${ }^{2}$ As a result gall-bladder bile becomes unsaturated with cholesterol $^{3}$ and can then dissolve cholesterol from the gallstone surface. ${ }^{4}$ By contrast, untreated patients with gall stones have fasting gall-bladder bile that is supersaturated with cholesterol ${ }^{5}$ - the cholesterol concentration exceeds the solubilising capacity of the bile acids and phospholipid present in bile, so that the cholesterol precipitates to form gall stones.

Certain conditions must be met for treatment with chenic acid to be widely accepted by doctors. Firstly, its use must be limited to patients likely to benefit from it, so that treatment failures do not bring it into disrepute. From the mechanism of its action treatment can be effective only for cholesterol gall stones, and it can dissolve these only if unsaturated bile can enter the gall bladder. These two requirements can be predicted from an oral cholecystogram that shows radiolucent 